\title{
Risk Assessment for Regional Flood Disaster in Hubei Province based on GIS
}

\author{
Dejian Liang, Hong Du *, Qian Gui, Tong Su, Zhiqiang Chen \\ College of Resources and Environmental Science, South-Central University For Nationalities, \\ Wuhan, Hubei province, China,430074
}

aemail,3559451296@qq.com

\begin{abstract}
Keywords: Flood disaster; Risk assessment; GIS; Analytic hierarchy process; Hubei province Abstract. Regional flood disaster risk assessment is an important part of regional flood disaster risk management. Taking the interaction among the disaster causing factors, the hazard inducing environment and the disaster bearing bodies into consideration, the risk assessment index system and model of flood disaster are established, then the analytic hierarchic process was used to confirm the weight of the indexes, fin ally the spatial analysis method based on Geographic Information System was carried out to assess the risk for flood disaster of Hubei province. The results show that: (1)The hazard degree of disaster causing factors is relatively high in the east and southwest part of Hubei province; (2) The sensitivity of hazard inducing environment in the east and southwest part of Hubei province are relatively high;(3)The vulnerability of disaster bearing bodies in the Jianghan plain area such as Wuhan city and the surrounding areas are high;(4)The area with high risk of flood disaster in Hubei province is mainly concentrated in the Jianghan plain, which is consistent with the actual situation.
\end{abstract}

\section{Introduction}

Flood disasters are mainly caused by rainstorms [1,2]. Under the effect of the hazard inducing environment on the redistribution of water, flood disasters can pose a threat to the disaster bearing bodies, such as population, transportation, residential housing, commerce and industry, employment, socio-economic system etc., and bring a lot of losses [3]. Therefore, the flood disaster assessment relates to the weather factors, the underlying surface factors and the regional socio-economic development situation, which show obvious spatial variability and can be termed as spatial data [4]. Geographic Information System (GIS) is a technical system for collecting, storing, managing, calculating, analyzing, displaying and describing the geographic data, which provides an effective method to describe the spatial variability of geographic data.

Generally, the qualitative assessment of regional flood risk is carried out by constructing the index system, which takes the formation condition of flood disasters and risk into consideration. Based on the long-time series data, the loss criterion of disaster-bearing body can be established, and the qualitative assessment of regional flood risk can be realized [2,5,6]. The flood risk assessment utilizes various indexes that affect the risk of flood disasters, and adopts a certain method or model to evaluate the flood hazard risk [7,8]. Thus, this paper takes the interaction among the disaster causing factors, the hazard inducing environment and the disaster bearing bodies into consideration, and the risk assessment index system and model of flood disaster are established, then the analytic hierarchic process was used to confirm the weight of the indexes, finally the spatial analysis method based on Geographic Information System was carried out to assess the risk for flood disaster of Hubei province.

\section{Research Regional Overview}

Hubei province is located from $29^{\circ} 05^{\prime} \mathrm{N}$ to $33^{\circ} 20^{\prime} \mathrm{N}$, from $108^{\circ} 21^{\prime} \mathrm{E}$ to $116^{\circ} 07^{\prime} \mathrm{E}$. The rivers, lakes and weather stations in the province are shown in Fig.1 [9,10]. Hubei province belongs to the subtropical monsoon climate area with abundant precipitation. The annual average temperature in Hubei province is $15 \sim 17^{\circ} \mathrm{C}$. The summer rainfall is $300 \sim 700 \mathrm{~mm}$, and the winter rainfall is $30-190$ $\mathrm{mm}$. The annual evaporation in the province is $600 \sim 1000 \mathrm{~mm}$. The distribution of precipitation is 
uneven in the province, which mainly concentrates in May to September, accounting for 60\% 70\% of the total annual precipitation.

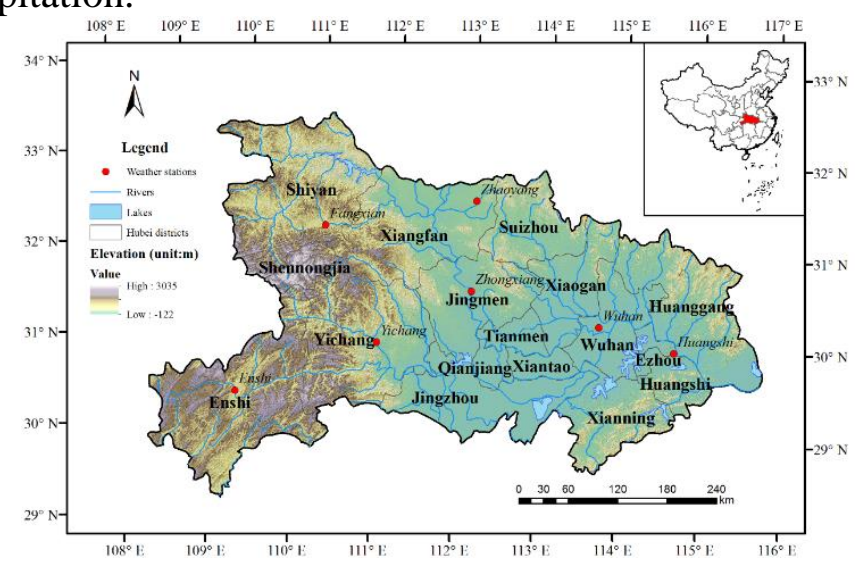

Fig. 1 Location map of Hubei province

\section{Data and Methods}

3.1 Data Sources. The data used in this study mainly include: (1) daily precipitation data of the main meteorological stations in Hubei province from 1978 to 2011 provided by China Meteorological Science Data Sharing Service Network; (2) DEM data with 90m resolution of Hubei province provided by the Geospatial Data Cloudwebsite; (3) River net data;(4) GDP statistic data, demographic data, and cultivated land data from 1978 to 2011 provided by the statistical yearbook of Hubei province.

3.2 Data Processing. Because of the different data sources, the different units and the large range of values, the data need to be standardized. In this study, the min-max method is used to standardize the data, and the standard values are in the range from 0 to 1 after standardization. The formula for data standardization is shown as follows:

$$
\begin{aligned}
& A=\left(B \_i-m i n\right) /(\max -\min ) \\
& A=\left(\max -B \_i\right) /(\max -\min )
\end{aligned}
$$

$\mathrm{A}$ is the result of standardization; $\mathrm{Bi}$ represents a data in a group; max represents the maximum value in a group of data; min represents the minimum value in a group of data.

The formula (1) is applied to standardize the indexes data, which can bring higher risk of flood, such as rainfall, GDP statistics, demographic data, cultivated area data, etc.; formula (2) is applied to standardize the indexes data, which can cause lower risk of flood, such as elevation, slope and so on.

\subsection{The Method of Risk Assessment and the Construction of Index System}

3.3.1 Risk Assessment Method. Based on the formation mechanism of flood disaster, its occurrence and development are affected by the natural geographical environment factors, human factors and socio-economic factors. Therefore, considering the disaster causing factors (hazard degree), the hazard inducing environment(sensitivity) and the disaster bearing bodies (vulnerability), the risk assessment of the flood disaster is achieved through the risk assessment model [11]. The risk assessment model of flood disaster adopted in this study is shown as follows:

$$
\begin{array}{r}
\mathrm{R}=\mathrm{W} \_\mathrm{h} * \mathrm{H}(\mathrm{x})+\mathrm{W} \_\mathrm{s} * \mathrm{~S}(\mathrm{x})+\mathrm{W}_{-} \mathrm{V} * \mathrm{~V}(\mathrm{x}) \\
\mathrm{H}(\mathrm{x})=\sum_{\mathrm{i}=1}^{\mathrm{n}}\left[\mathrm{W}_{\mathrm{i}} \times \mathrm{H}_{\text {ni }}(\mathrm{x})\right] \\
\mathrm{S}(\mathrm{x})=\sum_{\mathrm{i}=1}^{\mathrm{n}}\left[\mathrm{W}_{\mathrm{i}} \times \mathrm{S}_{\text {ni }}(\mathrm{x})\right] \\
\mathrm{V}(\mathrm{x})=\sum_{\mathrm{i}=1}^{\mathrm{n}}\left[\mathrm{W}_{\mathrm{i}} \times \mathrm{V}_{\mathrm{ni}}(\mathrm{x})\right]
\end{array}
$$


Where: $\mathrm{R}$ is the risk of flood disaster; $\mathrm{H}$ is the hazard degree of disaster causing factors; $\mathrm{S}$ is the sensitivity of hazard inducing environment; $\mathrm{V}$ is the vulnerability of the disaster-bearing bodies; W is the weights of influence factors.

3.3.2 Construction of Risk Evaluation Index System. According to the formation principle and the risk assessment model of flood disaster, this study selected the indexes of the disaster causing factors, the hazard inducing environment and the disaster bearing bodies. The annual rainfall, the days of annual rainstorms are indexes of the disaster causing factors, the average elevation, the river network density are the indexes of the hazard inducing environment $t$, and the GDP, the population density, the cultivated land area are the indexes of the disaster bearing bodies. So, the risk assessment index system of the flood disaster is established as follows (Fig. 2).

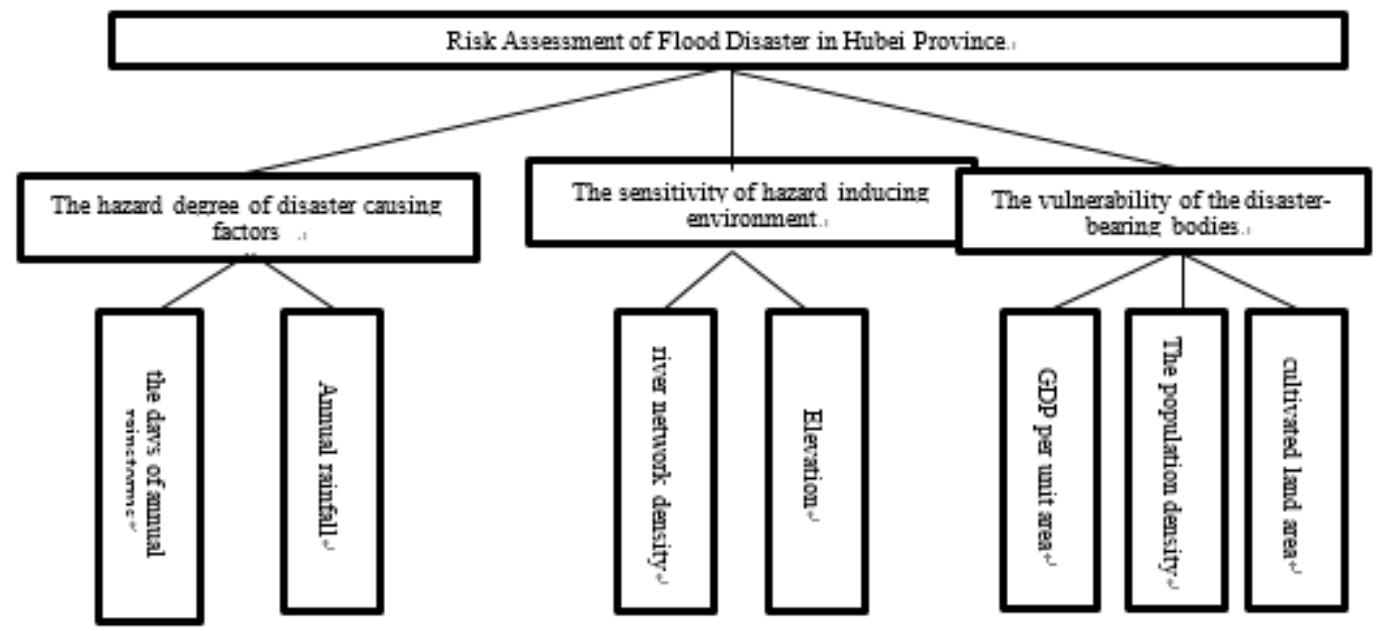

Fig. 2 Risk assessment index system of flood disaster in Hubei Province

3.3.3 Determination of Indicator Weight - Analytic Hierarchy Process. Analytic Hierarchy Process (AHP) method is a multiple criteria decision-making tool which combines qualitative and quantitative analysis. Rather than prescribing a "correct" decision, the AHP helps decision makers find one that best suits their goal and their understanding of the problem. Users of the AHP first decompose their decision problem into a hierarchy of more easily comprehended sub-problems, each of which can be analyzed independently [11]. Once the hierarchy is built, the decision makers systematically evaluate its various elements by comparing them to one another two at a time, with respect to their impact on an element above them in the hierarchy. In making the comparisons, the decision makers can use concrete data about the elements, but they typically use their judgments about the elements' relative meaning and importance. It is the essence of the AHP that human judgments, and not just the underlying information, can be used in performing the evaluations. [12].

\section{Results Analysis}

4.1 Calculation of the Weights of Risk Evaluation Indexes. In this study, AHP was used to calculate the weight of the risk assessment indexes of flood disaster in Hubei province. The results are shown in Table 1. It indicates that the weight of the two indexes - the days of annual rainstorms and the annual rainfall is larger, which are the main influence factors for the formation of flood risk in Hubei province.

Table 1 The weight of flood disaster risk evaluation indexes in Hubei province

\begin{tabular}{cc}
\hline index & Weight \\
\hline days of annual rainstorms & 0.27 \\
annual rainfall & 0.27 \\
river network density & 0.09 \\
elevation & 0.18 \\
the population density & 0.09 \\
GDP per unit area & 0.06 \\
cultivated land area & 0.04 \\
\hline
\end{tabular}


4.2 The Hazard Degree of Disaster Causing Factors. The disaster-causing factors is the main drive force of flooding [13]. In the study the disaster-causing factors involve two indexes - the days of annual rainstorms and the annual rainfall. The annual rainfall is the sum volume of rainfall in one year (mm). According to the precipitation levels (Table 2), if the 24 hours' cumulative rainfall is more than $50 \mathrm{~mm}$, which can be considered as rainstorm. The days of annual rainstorms is the cumulative days of rainstorm in the weather stations from 1978 to 2011.

Table 2 Precipitation levels (unit: $\mathrm{mm}$ )

\begin{tabular}{ccc}
\hline Grade & 12 hours' rainfall & 24 hours' rainfall \\
\hline Trace rainfall & $<0.1$ & $<0.1$ \\
Light rain & $0.1 \sim 4.9$ & $0.1 \sim 9.9$ \\
Moderate rain & $5.0 \sim 14.9$ & $5.0 \sim 29.9$ \\
Heavy rain & $15.0 \sim 29.9$ & $30.0 \sim 49.9$ \\
Rainstorm & $30.0 \sim 69.9$ & $50.0 \sim 99.9$ \\
Heavy rainstorm & $70.0 \sim 139.9$ & $100.0 \sim 249.9$ \\
Torrential rain & $>140$ & $>250$ \\
\hline
\end{tabular}

As the rainfall data is measured at the location of the weather stations, which cannot cover all the area of Hubei province, so the meteorological data should be treated with interpolation. This study uses the inverse distance weighting method(IDW) to undertake the interpolation based on the ArcGIS10.2 software platform, as shown in Figure 3. From Figure 3, the hazard degree of disaster causing factors is relatively high in the east and southwest of Hubei province.

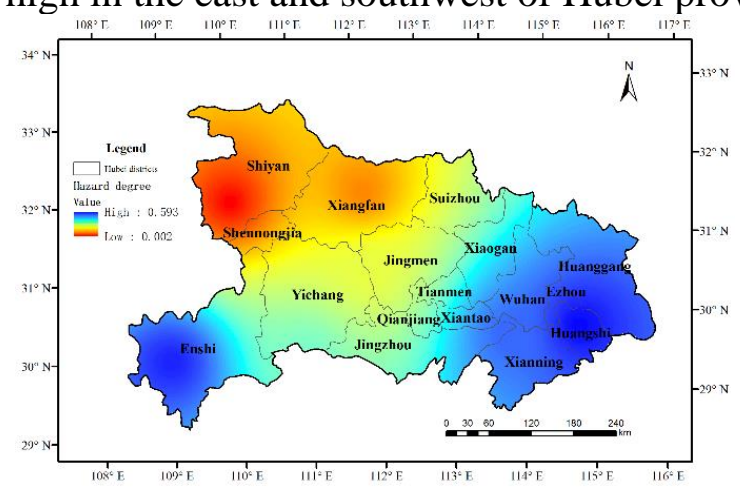

Fig. 3 The hazard degree of disaster causing factors in Hubei province

4.3 The Sensitivity of Hazard Inducing Environment. The hazard inducing environment is the natural and human environment, which is mainly referred to the underlying surface [12]. Therefore, this study calculates the standard deviation of relative elevation and the river network density based on ArcGIS 10.2, furthermore plots the spatial distribution map of sensitivity of hazard inducing environment in Hubei province (Fig. 4). It can be seen from the figure that the sensitivity of disaster environment in the southwest and east part of Hubei province is relatively high.

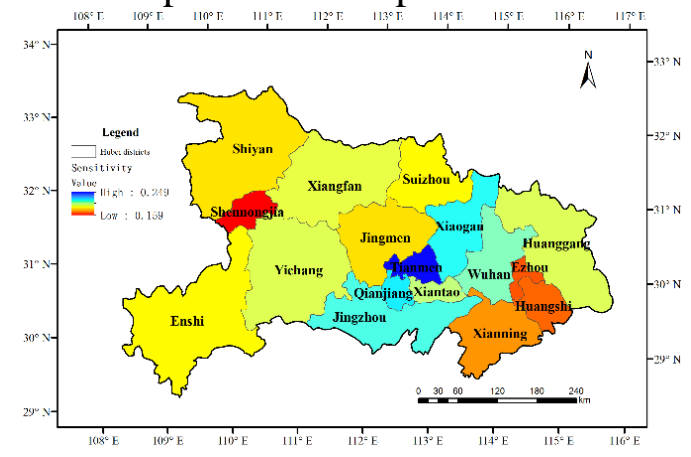

Fig. 4 The sensitivity of hazard inducing environment

4.4 The Vulnerability of Disaster Bearing Bodies. The regional socio-economic situation, 
including population, GDP, reflects the vulnerability of flood disaster, which show obvious spatial characteristics [13]. Based on the ArcGIS10.2 software platform, the paper draws a spatial distribution map of the vulnerability of the disaster bearing bodies in Hubei province (Fig. 5). From the figure, the vulnerability of the disaster bearing bodies is relatively high in the area of Jianghan plain, such as Wuhan and the neighboring cities.

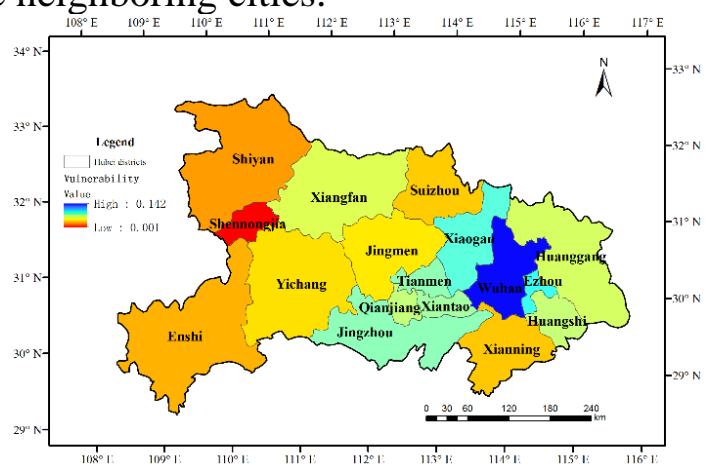

Fig. 5 The vulnerability of disaster bearing bodies

4.5 Comprehensive Risk Assessment of Flood Disaster. Flood hazard risk was the result of the disaster causing factors, the hazard inducing environment and the disaster bearing bodies. According to the risk assessment model of flood disaster, the flood hazard risk in Hubei province is evaluated comprehensively. As shown in Figure 6, during1978-2011, the southwest and east part of Hubei province, such as Wuhan and Enshi, in which the risk of local flood disaster is relatively high. The risk of local flood disaster in Yichang, Jingmen and Suizhou area is moderate, and which in the northwest part of Hubei province such as Shiyan and Shennongjia area is relatively low.

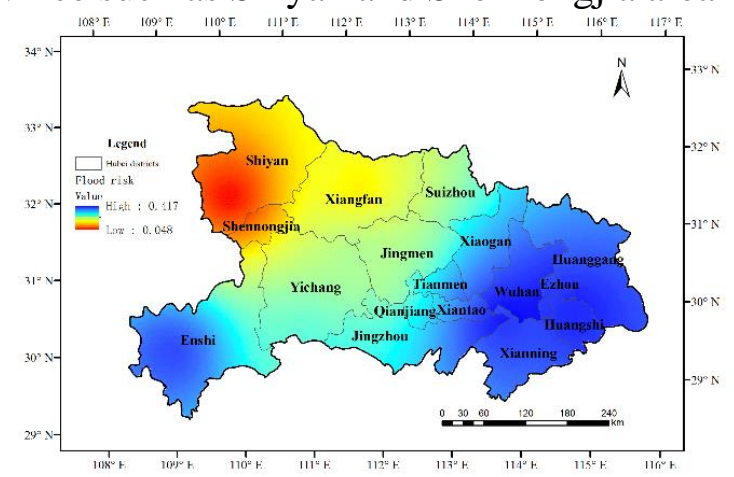

Fig. 6 Risk map of flood disaster in Hubei Province

\section{Conclusion}

This paper takes the interaction among the disaster causing factors, the hazard inducing environment and the disaster bearing bodies into consideration, and constructs the risk assessment index system and model of flood disaster for Hubei province, then uses the analytic hierarchy process to determine the weight of each index. Based on the spatial analysis method of geographic information system, the risk of flood disaster in Hubei province is evaluated.

The results show that: (1)The hazard degree of disaster causing factors is relatively high in the east and southwest part of Hubei province; (2) The sensitivity of hazard inducing environment in the east and southwest part of Hubei province are relatively high;(3)The vulnerability of disaster bearing bodies in the Jianghan plain area such as Wuhan city and the surrounding areas are high;(4)The area with high risk of flood disaster in Hubei province is mainly concentrated in the Jianghan plain, which is consistent with the actual situation.

\section{Acknowledgements}

This work was financially supported by "the Fundamental Research Funds for the Central Universities", South-Central University for Nationalities (CZQ15004); Innovation and entrepreneurship training program of South-Central University For Nationalities (XCX15022). 


\section{References}

[1] C H Zhou, Q Wan, S F Huang, et al. A GIS-based approach to flood risk zonation. Acta Geographica Sinica, Vol.55-1(2000),p. 15-24.

[2] J Yin, Z Y Pei, X W Chen, et al. GIS-based flood disaster risk assessment in Wuling Mountain region .Transactions of the Chinese Society of Agricultural Engineering, Vol.29-24(2013),p. 110-116.

[3] W J You, Y L Zhang, et al. Research on Social Vulnerability Index of Flood.Journal of Catastrophology, Vol.28-3(2013),p. 215-220.

[4] H 1 Chen, G D Chen, P Guo, et al. A GIS-based approach to risk assessment of Regional Flood. Yangtze River, Vol.34-6(2003), p. 49-51.

[5] $\mathrm{K} \mathrm{Z} \mathrm{Li,} \mathrm{S} \mathrm{H} \mathrm{Wu,} \mathrm{E} \mathrm{F} \mathrm{Dai,} \mathrm{et} \mathrm{al.Flood} \mathrm{loss} \mathrm{analysis} \mathrm{and} \mathrm{quantitative} \mathrm{risk} \mathrm{assessment} \mathrm{in}$ China.Natural Hazards, Vol. 63(2012), p. 737-760.

[6] K Z Li, Risk Assessment of Flood Disaster Loss in China. Beijing: Chinese Academy of Sciences Graduate School of Doctoral Dissertation,2011.

[7] J F Liu, Y H Liang, G B Ma, A GIS-based approach to risk assessment of Flood Disaster in Huaihe River Basin. Journal of Anhui Agricultural Sciences, Vol. 38-5(2010), p. 2510-2511,2561.

[8] X Zhao, P Wang, Y L Gong, J Tan, X R Li. A GIS-based approach to risk assessment of flood disaster in central Inner Mongolia. Journal of Beijing Normal University (Natural Science), Vol. 439-6(2007), p. 666-669.

[9] J Wan, Y H Zhou, Y Y Wang, G F Guo . A GIS-based approach to study on Risk Assessment Method of Flood Disaster in Hubei Province. Torrential Rain and Disasters, Vol. 26-4(2007), p. 328-333.

[10] B Y He, H L Zhang, S Zhang, Ding G P, et al. A GIS-based approach to risk assessment of Flood Disaster in Hubei Province. Journal of Natural Disasters, Vol. 11-4(2002), p.84-89.

[11] J Y Guo, Z B Zhang, Q Y Sun. Research and application of Analytic Hierarchy Process. China Safety Science Journal, Vol. 18-5(2008), p. 148-153.

[12] Y Q HU. Fundamentals and application of Operations research. Beijing: Higher Education Press,2014(6). 